\title{
O uso e ocupação do solo em projetos de mobilidade urbana: uma análise de soluções
}

\section{mitigadoras dos impactos construtivos}

\author{
Land use and occupation in urban mobility projects: an analysis of solutions to mitigate
} constructive impacts

Uso y ocupación del suelo en proyectos de movilidad urbana: un análisis de soluciones para mitigar impactos constructivos

\section{Resumo}

Historicamente, o Brasil tem privilegiado o modal de transporte rodoviário em consequência de políticas adotadas principalmente durante o século XX, que desenvolveu e estimulou o uso de transporte motorizado e privado, sendo isso, um dos pilares para o desenvolvimento de problemas com mobilidade urbana. Outro pilar que agrava esse problema é o processo que as cidades foram se desenvolvendo. Com êxodos rurais, o processo de favelização foi intensificado e a carência de políticas públicas para desenvolver infraestrutura adequada à essa parcela da população, trouxe o agravamento dos problemas locomotivos atuais no Brasil. As cidades brasileiras possuem bairros periféricos amplamente dependentes das regiões centrais, gerando grandes deslocamentos e consequentemente, dificuldades para adaptar todo esse transbordo em vias limitadas com estrutura insuficiente para a demanda. Como solução mais econômica para isso, o zoneamento misto deve ser aplicado utilizando conceito de fachada ativa nessas regiões dependentes do centro urbano. Com essa aplicação, reduziria a parcela da população que necessitaria de serviços e comércios em regiões distantes, consequentemente, reduzindo problemas de deslocamento urbano. Além de promover um desafogo aos problemas de mobilidade, o zoneamento misto é financeiramente uma solução mais viável em relação a obras de infraestrutura na malha viária urbana e construção de novos modais de transportes, podendo ser utilizado em todos os centros urbanos, independentemente do tamanho populacional.

Palavras-chave: Mobilidade urbana; Zoneamento; Transportes; Fachada.

\begin{abstract}
Historically, Brazil has privileged the road transport modal as a result of policies adopted mainly during the 20th century, which developed and encouraged the use of motorized and private transport, which is one of the pillars for the development of problems with urban mobility. Another pillar that aggravates this problem is the process that cities have been developing. With rural exodus, the slum process was intensified and the lack of public policies to develop adequate infrastructure for this portion of the population, brought the aggravation of current locomotive problems in Brazil. Brazilian cities have peripheral neighborhoods that are largely dependent on the central regions, generating large displacements and, consequently, difficulties in adapting all this transshipment along limited routes with insufficient structure for the demand. As a more economical solution for this, mixed zoning should be applied using
\end{abstract}


the concept of an active facade in these regions dependent on the urban center. With this application, it would reduce the portion of the population that would need services and commerce in distant regions, consequently, reducing urban displacement problems. In addition to providing relief from mobility problems, mixed zoning is financially a more viable solution in relation to infrastructure works in the urban road network and construction of new modes of transport, which can be used in all urban centers, regardless of population size.

Keywords: Mobility urban; Zoning; Transport; Facade.

\section{Resumen}

Históricamente, Brasil ha privilegiado el modo de transporte por carretera como resultado de políticas adoptadas principalmente durante el siglo XX, que desarrollaron y fomentaron el uso del transporte motorizado y privado, que es uno de los pilares para el desarrollo de problemas de movilidad urbana. Otro pilar que agrava este problema es el proceso que vienen desarrollando las ciudades. Con el éxodo rural se intensificó el proceso de los barrios marginales y la falta de políticas públicas para desarrollar la infraestructura adecuada para esta porción de la población, trajo el agravamiento de los problemas actuales de locomotoras en Brasil. Las ciudades brasileñas tienen barrios periféricos que dependen en gran medida de las regiones centrales, lo que genera grandes desplazamientos y, en consecuencia, dificultades para adecuar todo este transbordo por rutas limitadas y con estructura insuficiente para la demanda. Como solución más económica para esto, se debe aplicar la zonificación mixta utilizando el concepto de fachada activa en estas regiones dependientes del centro urbano. Con esta aplicación, se reduciría la porción de la población que necesitaría servicios y comercio en regiones distantes y, en consecuencia, se reducirían los problemas de desplazamiento urbano. Además de aliviar los problemas de movilidad, la zonificación mixta es financieramente una solución más viable en relación con las obras de infraestructura en la red vial urbana y la construcción de nuevos modos de transporte, que se pueden utilizar en todos los centros urbanos, independientemente del tamaño de la población.

Palabras clave: Movilidad urbano; Zonificación; Transporte; Fachada.

\section{Introdução}

A mobilidade urbana é um termo bastante utilizado para referir-se ao deslocamento de pessoas e veículos nas vias em todo o mundo. Esse termo ganhou uma abrangência enorme e passou a ser utilizado com maior frequência nos últimos anos, devido à preocupação com o crescimento das cidades e com a qualidade de vida no futuro próximo. O Brasil possui uma das maiores frotas de veículos automotivos do mundo, com mais de 54 milhões de automóveis em 2018 (DENATRAN, 2018). Essa frota sugere que o Brasil é um país majoritariamente movido pelo modal rodoviário. Segundo Júlio Cesar Lazaro da Silva, Mestre em geografia humana na UNESP, em matéria publicada pela UOL, isso está inteiramente relacionado ao fato de que desde os primeiros governantes na república velha passaram a implantar uma política rodoviarista forte, com o governo de Washington Luís (1926-1930), e sua famosa frase "Governar é povoar; mas, não se povoa sem se abrir estradas, e de todas as espécies; governar é, pois, fazer estradas", e passou a ser ainda mais efetivo com o governo Juscelino Kubitschek. O rodoviarismo no Brasil é bastante criticado por estudiosos por ter sido o modal prioritário durante décadas, e deixado em segundo plano os demais, como o aeroviário, ferroviário e hidroviário.

Com a chegada das primeiras montadoras de automóveis no Brasil, haviam estabelecido planos de desenvolvimento em infraestrutura para esse modal, com a construção de estradas e urbanização de cidades priorizando o transporte privado e individualista. Todo esse processo esteve bastante relacionado ao padrão de vida norte americana da época, em que o automóvel passa a ser ainda mais cobiçado no pós segunda guerra mundial sendo sinônimo de status e ainda com o barateamento realizado pelo empresário Henry Ford (empreendedor e engenheiro mecânico estadunidense, fundador da Ford Motor Company).

Segundo Amarolina Ribeiro, em publicação ao portal Brasil Escola, um fenômeno que impactou negativamente o controle de uso e ocupação do solo nas cidades brasileiras foi o êxodo rural, principalmente o ocorrido durante a década de 50 , período em que a industrialização estava alavancando no país.

Com o desemprego no campo, falta de educação e serviços essenciais, o êxodo rural é uma solução para pessoas buscarem melhores condições de vida em zonas urbanas, porém, com ele vem uma série de problemas como ocupações 
irregulares, superlotação, carência de infraestrutura dentre outros. A ocupação irregular dessas pessoas se dá pela falta de renda das mesmas. A velocidade que isso vem a acontecer, junto a ausência de controle total por parte do poder público em estabelecer planos de crescimento, fazem com que as cidades cresçam rapidamente, com a população ocupando áreas longe dos centros e necessitando a realização de grandes deslocamentos diários para poder trabalhar ou estudar.

Outros fatores contribuintes para o uso do transporte privado no Brasil é o aumento da renda média dos brasileiros e a redução de impostos pelo Governo Federal por parte de produtos industrializados. Em 2019, a renda domiciliar per capita no país aumentou 4,8\% comparado ao ano anterior, chegando a R\$ 1439 (IBGE, 2020). A grande acessibilidade de garantir um veículo próprio, em cidades com supervalorização dos meios automotivos, demonstram atualmente a grande dificuldade de reverter isso, principalmente por garantir uma sensação de segurança maior ao proprietário do veículo em relação as condições adversas e pouco atrativa de outras formas de deslocamento. A carência de conforto e a grande quantidade de obstáculos, podem ser alguns dos fatores que tornam os passeios públicos menos atrativos aos usuários. Obstáculos esses como a grande quantidade de irregularidades no pavimento, pouca acessibilidade, baixo conforto térmico e a falta de interação entre o ser humano e a fachada das edificações, que contribuem bastante com a falta de segurança e atratividade para o pedestre.

A pesquisa tem como objetivo identificar a origem de problemas de mobilidade urbana, apontando os principais fatores de causa, decorrente em boa parte das cidades brasileiras, propondo soluções que busquem estimular a redução do uso de transportes privados através do zoneamento e ocupação do solo.

O estudo foi formulado através de pesquisas bibliográficas exploratória, que é uma forma de levantamento de informações sobre o assunto através de trabalhos científicos que já abordaram tema semelhante, de modo que, a pesquisa possa ser melhor compreendida e trabalhada suas ideias.

\subsection{Problematização}

Vários problemas urbanos ocasionados em décadas passadas refletem atualmente, maximizando a dificuldade de estabelecer um sistema de mobilidade urbana suficiente e sustentável a população.

Quando se trata do conceito de mobilidade urbana, logo se é pensado na execução de viadutos, tuneis, vias expressas, linhas de BRT (Bus Rapid Transit), VLT (Veículo Leve sobre Trilhos) ou metrô, em que geralmente são obras muito caras e as vezes burocráticas de serem implantadas. Porém, as grandes metrópoles brasileiras, que possuem essa infraestrutura de transportes lidam com intensos problemas de mobilidade urbana, e cabe o questionamento se essa infraestrutura é suficiente para a demanda ou se existe outros empecilhos, que deverão ser investigados, ocasionando tais problemas na mobilidade urbana.

Esses possíveis empecilhos podem facilmente estarem relacionados ao uso e ocupação do solo das cidades, pela forma como se é distribuído os empreendimentos, gerando problemas de ergonomia urbana. Além de problemas de infraestrutura relacionado ao detrimento de ambientes que possam ocasionar a preferência do uso de transportes motorizados para pequenas distâncias, como por exemplo, a carência de acessibilidade em passeios.

O portal Mobilize Brasil, plataforma com conteúdo sobre a mobilidade sustentável brasileira, criou em setembro de 2019 uma pesquisa sobre os problemas registrados em calçadas pelas 27 capitais, que são: regularidade do piso, largura da calçada, inclinação transversal da calçada, existência de barreiras e obstáculos, condições de rampas de acessibilidade, faixas de pedestres, semáforos de pedestres, mapas e placas de orientação, arborização e paisagismo, mobiliário urbano, poluição atmosférica, ruído urbano e segurança. Considerando todos os itens avaliados, a nota obtida pelos pesquisadores da Mobilize Brasil foi 5,71, a nota mínima aceitável seria 8. Com esse estudo, é possível ter a noção do porque o transporte veicular é bem mais privilegiado no Brasil, e principalmente porque as cidades vêm lidando com problemas de engarrafamento e pouca 
sustentabilidade. Vale ressaltar, que o estudo citado foi realizado apenas nas 27 capitais do país, que geralmente são cidades que possuem uma infraestrutura relativamente melhor que as demais.

Figura 1 - Rua com o conceito de fachada ativa em Nova Iorque e rua em bairro residencial no Brasil respectivamente.

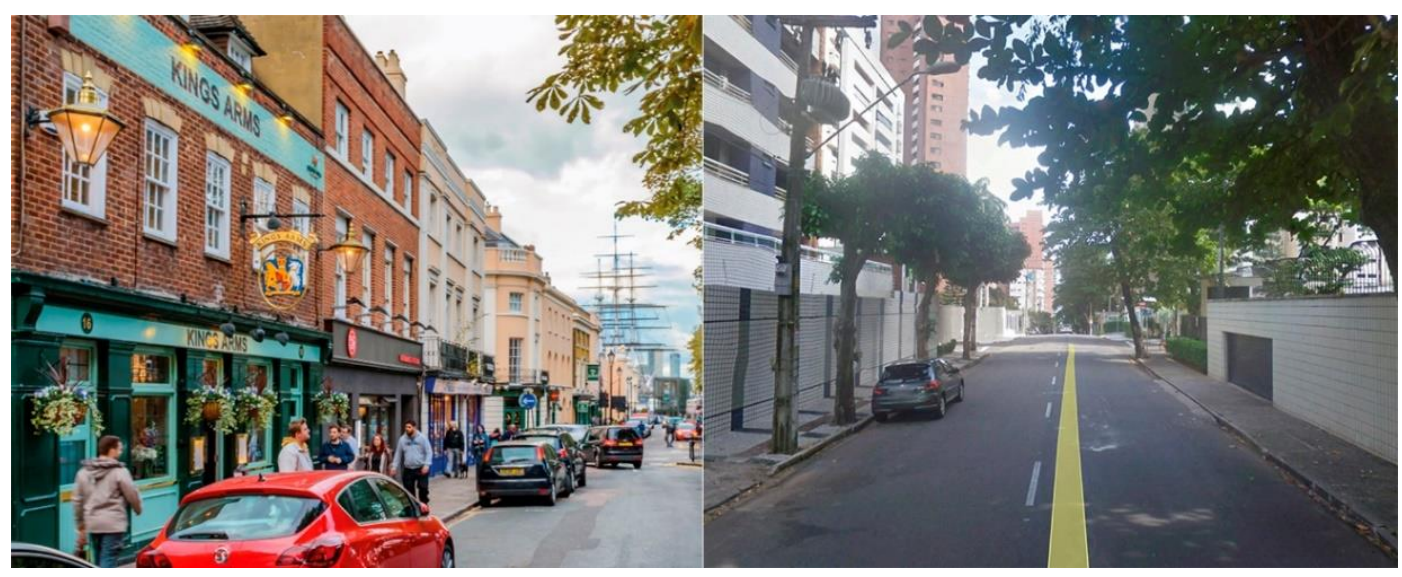

Fonte: Anthony Ling (2018); Projeto Batente (2017).

Diante do cenário brasileiro, com políticas majoritariamente rodoviaristas em décadas passadas, com cidades desenvolvidas priorizando o transporte individual e a carência de um transporte coletivo eficiente, que consiga atender em perfeitas condições a população, é necessário estudar soluções que possam minimizar tal problema de maneira economicamente viável e respeitando as questões sociais e ambientais.

Sendo assim, é questionável: A atual infraestrutura urbana das cidades é suficiente para a demanda? Quais os atuais problemas de mobilidade urbana que deverão ser identificados na busca de soluções que estimulem a redução do uso de transportes privados através do zoneamento e ocupação do solo?

\subsection{Justificativa}

Com o crescimento populacional, as cidades passarão a possuir uma demanda muito maior de infraestrutura viária que garanta a vivencia dos habitantes, porém, com um território muito amplo e crescente para a região periférica irá acarretar na saturação do sistema viário atual para a região central, onde possuem grande parte dos serviços e comércios de uma cidade.

Um dos objetivos dessa pesquisa é estabelecer propostas que estimulem o transporte de pessoas não motorizado para pequenas distâncias, com isso, deve ser levado em consideração a qualidade de toda a infraestrutura presente. Cidades que possuem passeios com boa caminhabilidade, são cidades com menos fluxo de carros nas ruas, sem transporte coletivo saturado e melhor saúde para as pessoas.

Esse estudo tem uma importância fundamental por ser um problema mundialmente discutido, de como os habitantes e seus deslocamentos no meio urbano devem passar a serem adaptados para garantir uma sustentabilidade e como deve ser gerido cidades mais acessíveis e confortáveis.

Um dos maiores problemas urbanos relacionado a mobilidade é como estar o uso e ocupação do solo. Desta forma, estabelecer diretrizes que modifiquem o cenário urbano para priorizar os pedestres e ciclistas e reduzir o número de transportes motorizados privados é essencial, desde que estas soluções sejam economicamente viáveis e sustentáveis. Um instrumento básico para orientar a atuação do poder público e da iniciativa privada na construção civil é o Plano Diretor. Nele é definido a ordem do crescimento de cidades visando garantir o pleno desenvolvimento sustentável e o bem-estar dos habitantes. Mas, 
infelizmente é uma tarefa árdua garantir a plena diretriz estabelecida no Plano Diretor, muito por causa de fatores socioeconômicos, culturais e políticos.

As vias destinadas aos pedestres e ciclistas na maioria das vezes ficam em segundo plano em relação a prioridade da malha viária das cidades, portanto, acabam por se tornarem pouco atraentes ou irrelevantes aos usuários. Exemplo disso se dá pela irregularidade do pavimento de calçadas e ciclovias, a baixa acessibilidade e a falta de uma infraestrutura adequada para gerar conforto aos usuários e a carência de atratividade.

Para isso, é fundamental que haja um atrativo a geração de fluxo de pessoas por elas. Um método construtivo importantíssimo na valorização das calçadas se dá pela instalação de empreendimentos em suas margens, tornando uma calçada viva, com fluxo constante de pessoas, garantindo uma segurança aos usuários, porém, esses empreendimentos possuem uma dificuldade de instalação não somente pela burocracia e das condições financeiras impostas, mas também pela pouca disponibilidade de locais. Em bairros adensados majoritariamente residenciais e verticalizados, muito das vezes esses imóveis são condomínios fechados, com paredes altas em suas fachadas, que tornam o ambiente externo pouco atrativo e seguro aos pedestres.

Figura 2 - Edificação mista com fachada ativa.

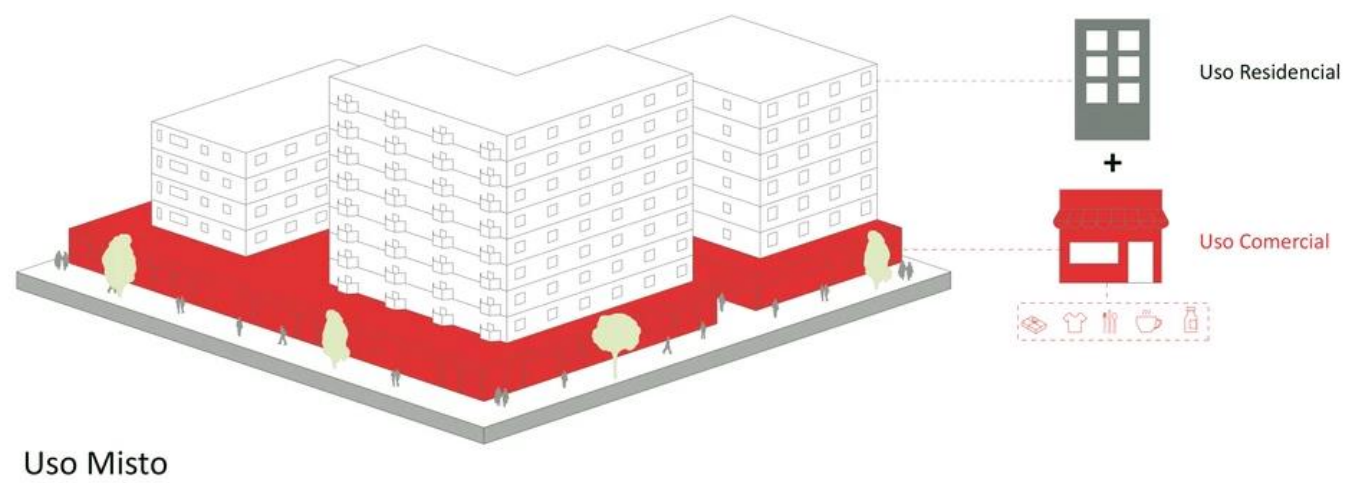

Fonte: IDOM - Consulting, Engineering \& Architecture (2018).

Logo, esse trabalho se justifica no estudo de maneiras que possam contribuir positivamente com a mobilidade urbana, a fluidez, praticidade, sustentabilidade e economicamente viáveis, através dos conceitos abordados.

\subsection{Objetivo}

O objetivo desse estudo é identificar a origem de problemas de mobilidade urbana, apontando os principais fatores de causa, decorrente em boa parte das cidades brasileiras, propondo soluções que busquem estimular a redução do uso de transportes privados através do zoneamento e ocupação do solo.

\section{Metodologia}

No presente artigo, o estudo de caso foi formulado através de pesquisas bibliográficas exploratória, que é uma forma de levantamento de informações sobre o assunto através de trabalhos científicos que já abordaram tema semelhante, de modo que, a pesquisa possa ser melhor compreendida e trabalhada suas ideias.

Pesquisa exploratória é quando a pesquisa se encontra na fase preliminar, tem como finalidade proporcionar mais informações sobre o assunto que vamos investigar, possibilitando sua definição e seu delineamento, isto é, facilitar a 
delimitação do tema da pesquisa; orientar a fixação dos objetivos e formulação das hipóteses ou descobrir um novo tipo de enfoque para o assunto. Assume, em geral, as formas de pesquisa bibliográficas e estudos de caso. (Prodanov \& Freitas, 2013).

A pesquisa bibliográfica é então feita com o intuito de levantar um conhecimento disponível, sobre teorias, a fim de analisar, produzir ou explicar um objeto sendo investigado. A pesquisa bibliográfica visa então analisar as principais teorias de um tema, e pode ser realizado com diferentes finalidades. (Chiara \& Kaimen et al, 2008. apud Tybel \& Douglas, 2008).

\section{Referencial Teórico}

O conceito de mobilidade urbana se apoia em quatro pilares: (i) integração do planejamento do transporte com o planejamento do uso do solo; (ii) melhoria do transporte público de passageiros; (iii) estímulo ao transporte não motorizado; e (iv) uso racional do automóvel. (Tribunal de Contas da União, 2015).

Segundo o (Ipea, 2010), “O padrão de mobilidade da população brasileira vem passando por fortes modificações desde meados do século passado, reflexo principalmente do intenso e acelerado processo de urbanização e crescimento desordenado das cidades, além do uso cada vez mais intenso do transporte motorizado individual pela população.” (Carvalho, 2016).

O aumento das frotas de automóveis e de motocicletas é uma tendência bastante forte no Brasil nos últimos anos, decorrente da elevação do poder aquisitivo, das deficiências do transporte público, bem como do apoio do governo federal para aquisição de veículos individuais, na forma de isenções de impostos e facilidades financeiras. (Tribunal de Contas da União, 2015).

De acordo com o (Ipea, 2011), “Outro aspecto importante da interação entre crescimento urbano e mobilidade é a forma excludente como as cidades crescem, com a ocupação das áreas mais periféricas pelos mais pobres. Isto significa que o custo do transporte vai aumentando à medida que as fronteiras urbanas se expandem em função das maiores distâncias percorridas e também pela característica de cidades dormitórios das novas ocupações periféricas, que reduzem a rotatividade de uso do transporte público, aumentando seu custo unitário.” (Carvalho, 2016).

Orientar a produção imobiliária para áreas localizadas ao longo dos eixos de transporte coletivo público com novas formas de implantação de empreendimentos que promovam melhores relações entre os espaços públicos e privados e contribuam para a redução dos tempos e distâncias de deslocamentos. (São Paulo, Lei 16.050 de 2014).

Calçadas devem ser largas, lisas, sem buracos e sem degraus ou rampas muito inclinadas, que impeçam a passagem, por exemplo, de um carrinho de bebê. Devem ser dotadas de rampas de acessibilidade e de toda a sinalização que proporcione a travessia segura nas esquinas: faixas de pedestres, placas de orientação e semáforos, programados com tempo suficiente para que um idoso possa cruzar a rua sem atropelos. E mais: sempre que possível, devem ser protegidas por arborização, para conforto de quem anda sob o sol, especialmente nestes dias quentes do verão brasileiro. (Sousa, 2014).

A cidade norte-americana (Portland) implantou o conceito de "bairro de 20 minutos", segundo o qual trabalho, escolas, centros comerciais, hospitais, restaurantes e centros de lazer e entretenimento estão a menos de 20 minutos de caminhada das casas, reduzindo os grandes deslocamentos e permitindo que as pessoas façam tarefas cotidianas a pé ou de bicicleta. (Reis, 2020).

Alguns parâmetros mais globais também devem ser analisados para a implementação das fachadas ativas, entre eles: localidades com densidade média ou alta, centralidades de bairros, vias de atividades, diversidades de usos, incentivo ao uso misto, relação entre os usos e atividades, padrões de mobilidade da população etc. (Kronenberger, 2017).

O zoneamento de uso e ocupação, mexendo com as atividades do privado e do particular, assim como suas taxas de incidência nos lotes, acaba definindo as qualidades intrínsecas, físicas e humanas do espaço público. Mas é uma regulação 
totalmente dependente das relações de forma dos agentes sociais que interagem na cidade. A presença ou não de um shopping ou loja de departamentos de grande superfície pode alterar toda vida e comercio de rua de suas vizinhanças. (Yázigi, 2000).

\section{Análise e Resultados}

Os Planos Diretores das cidades estabelecem normas e padrões construtivos que viabilizam a mobilidade, porém, algumas vezes os problemas não são solucionados e a garantia de adequação das cidades ao Plano Diretor não é uma tarefa fácil de ser imposta. Com isso, estabelecer soluções de melhorias do uso e ocupação do solo nas zonas urbanas para garantir uma boa mobilidade, é de fato uma estratégia vigente em países desenvolvidos que vem dando certo.

O investimento em formas de deslocamento não motorizado nos centros urbanos tem vários benefícios para a saúde e a sustentabilidade, para isso, deve-se desenvolver projetos que contemplem calçadas e ciclovias. O uso de edificações mistas, contendo em sua base empreendimentos, favorece a dinâmica de pessoas na região, tornando um espaço atrativo e minimizando a dependência de deslocamentos motorizados para habitantes próximos para algumas atividades. Sendo assim, estabelecer planos que estimulem esse conceito nas zonas urbanas, pode contribuir com a melhora da mobilidade de uma região.

A inserção de zonas mistas nas cidades terá uma boa eficiência caso sejam próximas a algum ponto de transbordo de pessoas, como terminais ou pontos de ônibus, com o intuito de formar "minicentros" comerciais em determinadas regiões de uma zona urbana.

Com a verticalização nas cidades, muitas vezes são formadas espécies de ilhas no cenário urbano, condomínios com grandes muros completamente delimitados das calçadas, tornando o ambiente externo desses condomínios inseguros e desconfortável aos pedestres, priorizando cada vez mais o transporte motorizado. A preferência por viver em residências ou condomínios totalmente murados, escondidos da rua é reflexo da criminalidade presente nas cidades brasileiras, porém, quanto mais fechado for uma edificação para o meio exterior, maior será a sensação de insegurança para as pessoas que percorrerão em seu entorno público.

O método de projeto de edificações verticalizadas bastante comum no Brasil é através da construção de torres isoladas no terreno, circundadas por muros geralmente altos, extensos e fechados, possuindo pouquíssima relação com o meio externo, formando ambientes contraditórios. Com a pouca relação com o entorno, esse padrão de edificações fornecem uma fachada inativa aos pedestres e uma necessidade de realização de deslocamentos motorizados para uma parcela dos habitantes, tanto da edificação, quanto da vizinhança. Desta forma, é proposto que em regiões majoritariamente residenciais, o incentivo e a destinação de lotes para a priorização de edificações multiuso. Esse incentivo além de possibilitar a melhor convivência e a mobilidade, também são aliados dos pequenos comércios ou serviços por garantir uma oportunidade.

Com a instalação de uma edificação mista em bairros amplamente residenciais, a dinamização do cenário desta região mudará, a sensação de insegurança aos moradores por conviver em ambientes pouco movimentados ou inativos também. O incentivo à produção de edificações mistas faz com que esses projetos atendam aos interesses comuns da cidade, harmonizando a vivencia dos pedestres e moradores do entorno obtendo também uma menor necessidade de deslocamento longo motorizado pois naquela edificação possa abrigar alguns estabelecimentos que supram algumas das necessidades dos moradores. Os usos de edifícios mistos não devem ficar restritos apenas a uma área da cidade nem a cidades populosas, devem haver projetos que possam ser inseridos em todas as regiões da zona urbana, principalmente nas periferias residenciais densas podendo ser aplicados em zonas urbanas de populações variadas.

Geralmente o padrão construtivo de fachada ativa é em sua grande maioria nas regiões centrais urbanas, porém, a dispersão desse método por toda a cidade cria uma descentralização e com isso, uma menor dependência de deslocamentos 
para a zona central. O conceito de descentralização gera uma qualidade na mobilidade urbana fundamental por poder minimizar os engarrafamentos e a saturação de vias principalmente nos horários de pico. As utilizações dessas edificações mistas nas regiões periféricas podem também serem integradas a uma mesma via que possua alta hierarquia para determinada região da cidade, desde que haja a infraestrutura correta, desta forma, a intensa ocupação por esse tipo de construção margeando uma mesma via pode formar um novo centro comercial.

O processo do planejamento urbanístico para o desenvolvimento sustentável está totalmente interligado às condições da mobilidade do local, o estímulo ao desenvolvimento de edificações mistas se dá como solução para evitar longos deslocamentos no meio urbano. Esse projeto de uso misto envolve simultaneamente o uso residencial e o não residencial em uma única estrutura. Para os residentes dessa edificação, tem a vantagem da fácil obtenção de algumas de suas necessidades com a praticidade de poder habitar sobre estabelecimentos comerciais. Já para a população que reside nas adjacências da edificação, o benefício também deve a praticidade de um menor deslocamento para a realização de algumas necessidades e para a vivacidade do entorno desse empreendimento.

\section{Conclusão}

Para uma boa mobilidade urbana é de extrema importância a melhoria de acessos e vias que priorizem o transporte público, pedestres e ciclistas. Essas melhorias devem acontecer através de adaptações na infraestrutura e nas características do entorno dessas vias, facilitando os deslocamentos e gerando maior conforto as pessoas que por ali passarão, além de apresentar um paisagismo adequado as condições climáticas da região para que haja um estimulo ao trânsito de pedestres e que a prática da caminhada seja a melhor forma de transporte urbano.

O investimento em formas de deslocamento não motorizado nos centros urbanos tem vários benefícios para a saúde e sustentabilidade. Sendo assim, deve-se desenvolver projetos que contemplem além de um transporte público eficiente, melhorias no zoneamento das cidades, buscando reduzir o grande deslocamento de pessoas para regiões mais concentradas de comércio e serviços. Através de soluções para distribuir empreendimentos por determinados pontos das cidades, as mais práticas acessibilidades a esses setores minimizam a necessidade de realizar longas distancias, geralmente com transporte motorizado, para alcançar tais serviços.

Com o aumento da população urbana a necessidade de espaço aumenta, e as soluções para que as edificações façam o máximo com o mínimo de espaço tornam-se cada vez mais frequentes nas grandes cidades. Sendo assim, o conceito de edificações mistas recebe uma importância grande para o contexto atual urbano, amontoando o máximo de coisas em uma edificação

Com isso, a inserção de zonas mistas nas cidades terá uma boa eficiência caso sejam próximas a algum ponto de transbordo de pessoas, como terminais ou pontos de ônibus, com o intuito de formar "minicentros" comerciais em determinadas regiões de uma zona urbana. Essa região mista poderá ser empregada em parcela de zoneamentos já existentes através da destinação de áreas em pontos mais acessíveis dessa zona, com o intuito de promover a criação de minicentros comerciais e de melhor distribuição de empreendimentos pela malha urbana.

\section{O cenário da pesquisa}

A pesquisa atendeu o objetivo proposto que buscava identificar a origem de problemas de mobilidade urbana, apontando os principais fatores de causa, decorrente em boa parte das cidades brasileiras. O estudo contemplou propostas de soluções que busquem estimular a redução do uso de transportes privados através do zoneamento e ocupação do solo, com ideias que integrem as edificações às vias urbanas, priorizando pedestres e ciclistas e atendendo algumas necessidades da 
população, minimizando a dependência de deslocamentos para regiões distantes que possam contribuir com problemas de mobilidade urbana.

Através do levantamento, contextualiza-se os atuais problemas de mobilidade urbana proporcionando possível solução para a redução do uso de transportes privados através do zoneamento e ocupação do solo.

O presente artigo trouxe à tona uma discussão de grande importância sobre o desenvolvimento das cidades a fim de torna-las mais sustentáveis e ergonômicas. Desta forma, fica o estimulo a novas pesquisas sobre esse tema para que haja novas propostas ou ideias complementares que possam desenvolver ainda mais as cidades, garantindo eficiência e minimizando impactos ambientais. Sugere-se, ainda, que outros estudos sejam desenvolvidos para discutir e fortalecer o tema da presente pesquisa, levando-se em consideração a evolução da sociedade e da mobilidade urbana, bem como os principais autores da área de engenharia civil.

\section{Referências}

Agencia IBGE Notícias. (2019) IBGE divulga o rendimento domiciliar per capita 2019.https://agenciadenoticias.ibge.gov.br/agencia-sala-de-imprensa/2013agencia-de-noticias/releases/26956-ibge-divulga-o-rendimento-domiciliar-per-capita-2019.

Bicalho, M. P. (2010). Os desafios da mobilidade urbana para o século XXI. Revista dos Transportes Públicos, Ano 32.

Boareto, R. (2008). A política de mobilidade urbana e a construção de cidades sustentáveis. Revista dos Transportes Públicos-ANTP-Ano, 30, 31-2008.

Campos, V. B. G., \& Ramos, R. A. (2005). Proposta de indicadores de mobilidade urbana sustentável relacionando transporte e u so do solo.

Carvalho, C. H. R. (2016) Desafios da Mobilidade Urbana no Brasil. Brasília: Ipea, 2016. http://repositorio.ipea.gov.br/bitstream/11058/6664/1/td_2198.pdf>.

Lima, M. R. T. R. (2006). Mobilidade urbana em planos diretores: análise sintática da malha viária da área conurbada de Florianópolis (Doctoral dissertation, Universidade Federal de Santa Catarina).

Estatuto, D. C. (2002). Guia para implementação pelos municípios e cidadãos: Lei no 10.257. de 10/7/2001, que estabelece diretrizes gerais da política urbana. (2a ed.), Câmara dos Deputados, Coordenação de Publicações.

Gentil, C. D. A. (2018). Influência da forma urbana na construção de um padrão de mobilidade urbana sustentável. In $8^{\circ}$ Congresso Luso-Brasileiro para o Planeamento Urbano, Regional, Integrado e Sustentável.

Instituto Brasileiro de Geografia e Estatística. (2011). Reflexões sobre os Deslocamentos Populacionais no Brasil. https://www.ibge.gov.br/estatisticas/sociais/populacao/9159-reflexoes-sobre-os-deslocamentos-populacionais-no-brasil.html?=\&t=sobre.

Kronenberger, B. C. Fachada Ativa. (2017) Governo do Distrito Federal, 2017. http://www.seduh.df.gov.br/wp-conteudo/uploads/2017/11/EstudoT\%C3\%A9cnico-Fachada-Ativa.pdf>.

Magagnin, R. C., \& Rostworowski, L. F. (2008). Os desafios da mobilidade urbana sustentável em cidades de médio porte: o caso de MARÍLIA (BRASIL) (Doctoral dissertation, Tese de Doutorado. Universidade de São Paulo. São Paulo).

Mello, E. D. S. (2008). Mobilidade urbana sustentável em projetos estruturantes: analise urbanística e ambiental do corredor de transporte da Avenida Bernardo Vieira Natal/RN (Master's thesis, Universidade Federal do Rio Grande do Norte).

Mobilize Brasil. (2020) Uma avaliação da caminhabilidade nas cidades brasileiras. https://www.mobilize.org.br/campanhas/calcadas-do-brasil-2019/ .

Mobilize. (2019) "Estudo revela a precariedade das calçadas nas 27 capitais brasileiras" 20. ArchDaily Brasil. https://www.archdaily.com.br/br/925043/estudorevela-a-precariedade-das-calcadas-nas-27-capitais-brasileiras>.

Pena. R. F. A. (2020). Rodoviarismo no Brasil. Mundo Educação. https://mundoeducacao.uol.com.br/geografia/rodoviarismo-no-brasil.htm.

Política Nacional de Mobilidade Urbana. (2015) Tribunal de Contas da União, 2015.https://portal.tcu.gov.br/biblioteca-digital/politica-nacional-demobilidade-urbana.htm>.

Prodanov, C. C., \& De Freitas, E. C. (2013). Metodologia do trabalho científico: métodos e técnicas da pesquisa e do trabalho acadêmico-2 ${ }^{\mathrm{a}}$ Edição. Editora Feevale.

Reis, M (2020) Mobilidade Urbana: Um desafio para gestores públicos. Fundação Getúlio Vargas.https://moodle.ufsc.br/pluginfile.php/23 77097/mod_resource/content/1/cidades_inteligentes_e_mobilidade_urbana_0.pdf >.

Ribeiro, A. (2020) "Efeitos do Êxodo Rural nos países subdesenvolvidos"; Brasil Escola.https://brasilescola.uol.com.br/geografia/efeitos-exodo-rural.htm.

Rodrigues, J., da Silveira Farias, E., \& Behr, A. (2013). Iniciativas e Tendências de Projetos de Mobilidade Urbana e Transporte Público a partir de uma Revisão Sistemática. Anais do Salão Internacional de Ensino, Pesquisa e Extensão. 
Research, Society and Development, v. 10, n. 15, e23101521883, 2021

(CC BY 4.0) | ISSN 2525-3409 | DOI: http://dx.doi.org/10.33448/rsd-v10i15.21883

Saboya, R. T. D. (2007). Construção de um sistema de suporte à elaboração de planos diretores participativos. Tese (doutorado) - Universidade Federal de Santa Catarina, Centro Tecnológico. Programa de Pós-Graduação em Engenharia Civil. http://repositorio.ufsc.br/xmlui/handle/123456789/90032

São Paulo. Lei $\mathrm{n}^{\circ} 16.050$ de 2014. (2014) Plano Diretor Estratégico do Município de São Paulo. São Paulo, SP. https://gestaourbana.prefeitura.sp.gov.br/projeto-de-lei-com-links/.

Scaringella, R. S. (2001). A crise da mobilidade urbana em São Paulo. São Paulo em perspectiva, 15, 55-59.

Scopel, V. G. (2017). Fachadas ativas: uma alternativa para a melhora da relação entre arquitetura e cidade. In IX Seminario Internacional de Investigación en Urbanismo, Barcelona-Bogotá, Junio 2017. Departament d’Urbanisme i Ordenació del Territori. Universitat Politècnica de Catalunya.

Seabra, L. O., Taco, P. W. G., \& Dominguez, E. M. (2013). Sustentabilidade em transportes: do conceito às políticas públicas de mobilidade urbana. Revista dos Transportes Públicos-ANTP, 35(134), 103-124.

Silva, J. C. L. (2020). O Processo de Globalização. Brasil Escola.

Silva, L. F. D. O. (2016). Mobilidade urbana e projetos estruturantes na região metropolitana de Natal: desafios recentes a uma metrópole em transformação (Master's thesis, Brasil).

Sousa, M. (2014) Mobilidade urbana começa na sua calçada. Mobilize Brasil, 2014. http://www.mobilize.org.br/noticias/6398/mobilidade-urbana-comeca-nasua-calcada.html>.

Tybel, Douglas. (2017) O que é pesquisa bibliográfica? Guia da Monografia, 2017. https://guiadamonografia.com.br/pesquisa-bibliografica/>.

Yázigi, E. (2000). O mundo das calçadas: por uma política democrática de espaços públicos. Humanitas, FFLCH/USP. 